\title{
ENTRE A PALAVRA E A AÇÃO: A FORMAÇÃO E A AUTOFORMAÇÃO
}

MELLO, Lucrécia Stringhetta ${ }^{1}$

\section{Resumo:}

O texto analisa o processo de constituição dos profissionais da educação no campo formativo tomando como princípio a perspectiva interdisciplinar de se pensar sob a intervenção significadora da prática simbólica. Para tanto, apoia-se em estudos científicos da área, assim como em experiência vivenciadas nos cursos de formação continuada e pesquisa do cotidiano envolvendo professores e gestores da educação básica. Compreende-se que o caminho formativo perpassa por instituições como família, escola e igreja além do conjunto das culturas e as regras existentes que vão desenhando o modo peculiar, pessoal e individual da história de cada um. Na prática os padrões de comportamento definem modos de agir e viver que podem ser desvelados por meio do autoconhecimento que, juntamente com a autoformação concorre para a autonomia de si ao desvelar os condicionamentos da estrutura social sob o prisma da consciência cognoscitiva e avaliativa instalando as representações daquilo que os individualiza e, junto aos pares os torna sujeitos coletivos.

Palavras chave: formação docente; autoformação; identidade.

\section{Abstract:}

The text examines the process of Constitution of the education professionals in the field of formation on the principle the interdisciplinary perspective of thinking under the significadora symbolic practice intervention. To this end, based on scientific studies of the area, as well as in experience experienced in continuing training courses and everyday research involving teachers and managers of basic education. It is understandable that the formational journey is by institutions such as family, school and Church in addition to the set of cultures and existing rules will drawing the peculiar, individual and personal history of each one. In practice the behavior patterns define ways to act and live that can be unveiled through the self-knowledge that, along with the personal formation, competes for the autonomy of himself by unveiling the conditionings of social structure under the prism of consciousness cognoscitiva and evaluative installing renditions of what the individualizes and together in pairs makes collective subjects.

\footnotetext{
${ }^{1}$ Doutora em Educação, Professora Associada da Universidade Federal de Mato Grosso do Sul, Campus de Três Lagoas e Profa. do Programa de Pós Graduação em Educação: Mestrado e Doutorado do CCHS/UFMS. Coordenadora da Linha de Pesquisa Educação, Psicologia e Prática Docente lucrecia.mello@uol.com.br
}

UNESC, Criciúma, v. 5, n¹, janeiro/Junho 2016. Criar Educação - PPGE UNESC 


\section{Criar Éducaçãa}

Keywords: teacher education; independent learning; identity.

\section{Introdução}

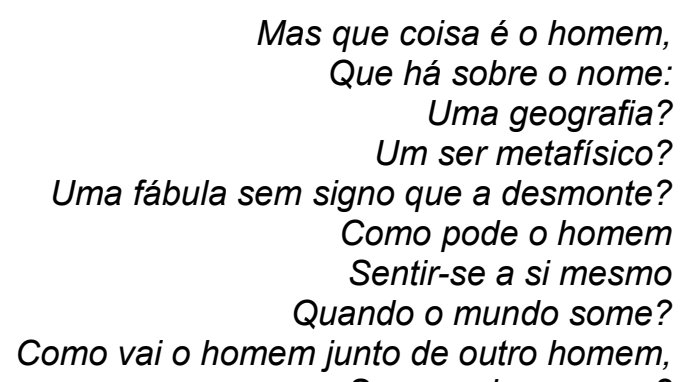

Sem perder o nome?

(Carlos Drumond de Andrade).

O poema de Drumond nos leva a refletir sobre o lugar em que vivemos as pessoas com as quais interagimos e como somos. O que há sobre o nome? O que construímos a partir do nome que nos é dado ao nascer? Quais as influências que recebemos no 'mundo vida' durante nosso caminhar? Como construímos e mantemos a identidade nominada no decorrer de nossa existência? Será que tudo se resume em formação? Um olhar escrutinador sobre nós mesmos, um olhar ao nosso redor pode analisar e perceber verdadeiramente $\mathrm{o}$ que está acontecendo com nossos padrões de comportamento e modos de agir arraigados e influenciados por aspectos afetivos, cognitivos, éticos e pelo contexto no qual estamos inseridos. Nos leva a refletir sobre a formação.

Explica Larossa, (1999, p. 52) que "o sentido do que somos depende das histórias que contamos e das que contamos de nós mesmos [...]". Assim é possível depreender que os sentidos, as narrativas constituem-se em elementos decisivos para orientar nosso agir e a favorecer a autoformação. As UNESC, Criciúma, v. 5, n¹, janeiro/Junho 2016. Criar Educação - PPGE UNESC 


\section{Criar Éducaçãa}

construções narrativas de cada um, em particular, traduz ao mesmo tempo, a autoria, o narrador e o 'personagem principal'. Para que isso se efetive recorrese à memória, pois por meio dela surgem as lembranças trazendo o passado ao presente. As lembranças vão se mesclando com as percepções do presente, ou vice-versa, as impressões do presente interagem com o passado e vai fixando na consciência. Não existe presente sem passado, as ações, os eventos, os comportamentos que vivenciamos são marcados na memória. (BOSI, 1983).

A prática de contar as próprias memórias seja verbalizada ou caracterizada por uma escrita reflexiva é um exercício de recordar narrando as experiências de um tempo passado, dos fatos que já ocorreram, para fazer suscitar na mente, além das recordações/lembranças, também informações que certamente constituirão novos sentidos no presente e que se constituem em nosso percurso formativo.

O olhar para a memória nos leva a um elemento dela inseparável que é a identidade constituída por vários fatores que a afetam e que podem ser resgatados na geografia do vivido dando compleição ao que se é. Dessa forma a formação de professores, seja ela inicial ou continuada deve garantir aos profissionais da educação instrumentos para que eles possam refletir não apenas sobre as teorias produzidas fora da sala de aula, mas, também para que desenvolvam suas teorias à medida que reflitam sobre suas ações em busca de uma mudança da prática.

Com essa compreensão, o texto é construído na perspectiva da interdisciplinaridade e aborda a complexa relação entre a formação, a autoformação, identidade com a intenção de abordar o percurso histórico percorrido do qual se tira saberes/lições que orientam as escolhas do viver.

\section{A prática do autoconhecimento na orientação do viver e da autoformação}

A prática de refletir sobre o lugar em que se vive, as pessoas com as quais interagimos, o trabalho que desempenhamos, como somos e as representações que temos desse complexo contexto é uma prática

UNESC, Criciúma, v. 5, nº1, janeiro/Junho 2016. Criar Educação - PPGE UNESC 
interdisciplinar. É o desfecho do olhar inquiridor de quem deseja constituir-se em sujeito de sua própria formação.

Transparece a necessidade do autoconhecimento, um olhar sobre si mesmo, um olhar sobre seu interior trazendo à tona o(s) paradigma(s) que comandam nosso agir e que determinam o desempenho de papeis, assim como, determina a capacidade técnica, política e humana do viver de cada um. Faz parte da proposta da autoformação a busca reflexiva sobre si mesmo sem esquecer da sua relação com o mundo vida sobre o qual procura construir o significado de seu trabalho. Supõe um enfoque de investigação-ação-formação. É um processo de constituição de significados e mobiliza assumir uma ética de que toda pessoa é portadora de significados.

"A formação é inevitavelmente um trabalho de reflexão sobre os percursos de vida" nos diz Nóvoa (2010, p.167) e Fazenda (2006) reitera sobre o quanto é importante pensar o novo por meio a uma visita ao velho com o recurso da memória. Para Fazenda a memória quando trabalhada,

[...] permitirá uma releitura crítica e multiperspectival dos fatos ocorridos nas práticas docentes, que poderão ajudar a compor histórias de vida dos professores, vidas que, cuidadosamente analisadas, poderão contribuir para revisão conceitual e teórica da didática e da educação. (FAZENDA, 2006, p. 13).

Quando a interdisciplinaridade orienta o agir, mais que um discurso ela incorpora uma atividade prática em que a teoria é apenas uma dimensão da prática. As práticas "no cotidiano educacional formam um ethos, em um modo de ser e de viver" (SEVERINO, 2002), mas ela não se autoesclarece apenas por efetivar-se. Sendo humana é intencional e nem sempre transparente.

O processo interdisciplinar de pensar é a intervenção significadora da prática simbólica, da consciência cognoscitiva e avaliativa a qual instaurará o sentido do viver. (SEVERINO, 2002). O que se argumenta é que a interdisciplinaridade humanizadora deve ser intencionalizada pela autoformação, um dos seus pressupostos epistemológicos como estratégia de refletir sobre si e as ações cotidianas engendradas no percurso histórico e no trabalho de cada um de modo a rever-se. É um processo de autonomia de si mesmo que vai sendo constituído centrado na pessoa ou no grupo, apoiado no UNESC, Criciúma, v. 5, n¹, janeiro/Junho 2016. Criar Educação - PPGE UNESC 


\section{Criar Éducaçãa}

coletivo. Trata-se de um poder pessoal por meio do qual cada um vai construindo significados 'sentindo-se a si mesmo', isto é refletindo na trajetória de formação, não apenas inicial, mas sim, em toda a vida.

De certa forma, as diversas facetas da autoformação acabam tendo o foco privilegiado na questão do paradigma que rege a finalidade principal de seu fazer (pedagógico/educativo) e nas interrelações pessoais coerentes com a filosofia de educação sob a qual rege sua conduta. A dimensão que alcança nesse processo é indicada pela forma como situa o ser humano - singular e igual - na busca da emancipação ou não, dependendo do eixo da horizontalidade ou verticalidade adotado.

A autoformação vista como um processo de autonomia de si, centrada na pessoa ou no grupo e apoiada no coletivo, ou seja, não é sinônimo de aprendizagem ilhada. Representa tomar o poder pessoal ou coletivo sobre a própria formação e, por ser crítica é um processo de emancipação e supõe a aceitação do inacabado e da incerteza. Representa uma autonomia que é jogada na interdependência.

Existem situações que são favoráveis à autoformação a exemplo de conflitos pedagógicos no campo de trabalho que levam o sujeito a pensar, a buscar em si mesmo respostas, assim como fatores negativos devido a situações amorfas no desempenho das funções e falta de motivação interior e dependência funcional para querer ser mais e melhor.

Portanto, a processo formativo ocorre por meio das interações pessoais, da reflexão sobre si e seu fazer. As mudanças de pensamento são possíveis com a aprovação interior que se dará com:

[...] a substituição da postura da resignação e passividade da consciência servil e alienada, obediente e acrítica, pela consciência ativa, que recria a si própria, isso porque as mudanças sociais passam, necessariamente, pela mudança individual. (grifos do autor) (ALGARVE, 1991 apud BORDIGNON; GRACINDO, 2009, p. 152).

$\mathrm{Na}$ diversidade de papéis que assumem os educadores, o estudo em grupo possibilita atingir a socialização de diferentes saberes originários de uma mesma prática refletida, pela troca de experiências em momentos que retomam aos estudos teóricos contrapondo-os com a vivência cotidiana. A vertente da

UNESC, Criciúma, v. 5, n¹, janeiro/Junho 2016. Criar Educação - PPGE UNESC 


\section{Criar Éducaçãa}

subjetividade é necessária nesse contexto, pois possibilita a hermenêutica dos sentidos produzidos nas falas Josso, (1999, p. 11) "a preocupação de dar ao trabalho sobre e com a subjetividade de um estatuto hermenêutico produzindo no mesmo movimento" leva a "[...] um conhecimento do processo de construção de si (self) e dos conhecimentos generalizáveis pelo seu valor de uso".

No percurso de construção e constituição do ser (do eu), produz-se a imantação de campos e práticas e, essa medida possibilita promover a consolidação de uma alternativa interdisciplinar de reflexão sobre si mesmo. Como já mencionamos a autoformação não é algo que acontece isoladamente, sinônimo de uma ilha isolada, pois, 'como pode o homem sentir-se a si mesmo quando o mundo some'. O conhecimento é um processo sinuoso, marcado por obstáculos e com resultados marcados pela ambiguidade;

Conhecer não é o ato através do qual um sujeito transformado em objeto, recebe dócil e passivamente os conteúdos que outro lhe dá ou Ihe impõe. O conhecimento pelo contrário, exige presença curiosa do sujeito em face do mundo. Requer sua ação transformadora sobre a realidade. Demanda uma busca constante. Implica invenção e reinvenção. (FREIRE, 1974, p. 37).

$\mathrm{O}$ ato de conhecer leva autoformação recomendada por Dewey (1916) em sua obra Democracia e Educação sinalizando que em uma sociedade móvel tem muitos canais de distribuição de mudanças que acontece em toda parte para que seus membros para iniciativa pessoal e para a adaptação. Mais adiante, em Fazenda (1991) observa-se a velha preocupação de que a autoformação não é sinônimo de ilha isolada. Revela-se na autonomia de si mesmo, centrada na pessoa ou no grupo, apoiado no coletivo e que requer o poder pessoal.

Esse processo é permanente, instável e por meio das relações de poder, dos significados o mundo, a educação, a identidade e a diferença tornam-se conhecíveis, inteligíveis e passíveis de serem representados. "As representações são tanto o efeito, o produto e o resultado de relações de poder e identidades sociais quanto seus determinantes" (SILVA, 1996, p. 171). A

UNESC, Criciúma, v. 5, n¹, janeiro/Junho 2016. Criar Educação - PPGE UNESC 


\section{Criar Éducaçãa}

identidade, a diferença, as representações são construídas socialmente e sempre serão ressignificadas pois os significados utilizados nas representações não são fixos, estáveis, definitivos. "O terreno do significado é um terreno de luta e contestação" (SILVA, 1996, p. 176).

A identidade é também uma questão cultural como nos aponta Hall:

Os seres humanos são seres interpretativos, instituidores de sentido.
A ação social é significativa tanto para aqueles que a praticam quanto
para os que a observam: não em si mesma, mas em razão dos
muitos e variados sistemas de significado que os seres humanos
utilizam para definir o que significam as coisas e para codificar,
organizar e regular sua conduta uns em relação aos outros. Estes
sistemas ou códigos de significado dão sentido às nossas ações. Eles
nos permitem interpretar significativamente as ações alheias.
Tomados em seu conjunto, eles constituem nossas "culturas" (HALL,
1997, p. 16).

A cultura compreendida como um processo de múltiplos significados por meio dos quais se dá sentidos ou não as próprias ações e às ações dos outros leva-nos ao entendimento de que toda ação social é também uma prática cultural. Nessa articulação é que as práticas culturais ganham ou não legitimidade até mesmo normalidade, naturalidade, essencialidade, cientificidade e como outras permanecem marginais. Quando elas se imbricam, se mesclam, misturam e se entrecruzam produzem novas identidades sempre abertas a novos processos de articulação, pois as identidades nunca se fixam nem na tradição, nem na natureza, nem em qualquer outra referência. As identidades culturais estão sempre se (re-)significando nas fronteiras porosas que caracterizam as culturas.

Por estar imbricada na atividade produtiva de cada indivíduo, nas condições sociais e institucionais a identidade é também uma questão política por levar ao questionamento dos espaços e possibilidades permitidas a cada indivíduo e aos outros de, sendo ele mesmo se transformar e se recriar. "Saber como chegamos a ser o que somos é condição absolutamente necessária, ainda que insuficiente, para resistir, para desarmar, reverter, subverter o que somos e o que fazemos" (Veiga Neto, 2003, p. 7).

UNESC, Criciúma, v. 5, n¹, janeiro/Junho 2016. Criar Educação - PPGE UNESC 


\section{Oriar Éducaçãa}

A problematização de nosso agir e ser é a maravilhosa incerteza do inacabado que leva a pensar, a criar, a pesquisar e, ouso acrescentar elucidar o sentido da existência.

\section{A formação acadêmica e a autoformação}

O conjunto de culturas contemporâneas que a sociedade vai produzindo, as relações conflituosas, ou mesmo pacífica torna-se potencial no processo de construção da identidade docente. Decorre que, os caminhos formativos escolhidos e o conjunto das culturas, as regras existentes vão desenhando o modo peculiar, pessoal e individual da história de cada um. A formação de profissionais críticos para atuar em condições complexas e incertas da escola nos remete não apenas a compreender que a identidade é uma questão cultural, social e política como também, a buscar um entendimento mais profundo das transformações que a sociedade vem sofrendo e das políticas públicas implantadas nas ultimas décadas que interferem nos modos de ser e de agir no campo da educação.

Quando a formação inicial ou continuada toma a compleição de uma simples presença como; receber objetos novos, uma técnica ou uma forma diferente de proceder em uma comunidade provoca atitudes que podem ser de desconfiança, de recusa, total ou parcial, assim como, de aceitação também. $O$ que não se pode negar é que, ao manter-se o nível de percepção do mundo, condicionado pela própria estrutura social em que se encontram os homens, estes objetos ou esta técnica, ou esta forma de proceder são manifestações culturais que podem ser percebidos magicamente e não criticamente. Daí a distorção que podem sofrer no novo contexto de formação ao qual foram inseridos de forma que a formação em si mesma (e quando não o é, está sendo mal dominada) enquanto ato de simples transferência de conhecimento, nada ou quase nada pode fazer no sentido de compor a história formativa.

No processo formativo o máximo que se pode fazer é 'mostrar', sem 'revelar' ou 'desvelar' aos indivíduos uma presença nova: a presença dos conteúdos estendidos. A captação destes, como mera presença, por si mesma, UNESC, Criciúma, v. 5, n¹, janeiro/Junho 2016. Criar Educação - PPGE UNESC 
não possibilita àqueles que os captam terem um verdadeiro conhecimento. É que mera captação dos objetos como das coisas é um puro dar-se conta deles sem ainda conhecê-los. O sujeito não pode ser compreendido fora de suas relações com o mundo, pois ao mesmo tempo em que é um 'ser-em-situação' é também um ser da práxis, da ação e da reflexão. Assim, somos levados a concluir que quanto mais observarmos as formas como se comporta e pensa em certas áreas (em maior ou menor grau) as quais estão próximos sentem-se como parte dele e não como seus transformadores.

Marli André também destaca a identidade docente como um elemento inseparável do desenvolvimento profissional e menciona a escola, as reformas e contextos políticos como fatores determinantes e que implicam na identidade. Ressalta que determinam "o compromisso pessoal, a disponibilidade para aprender a ensinar, as crenças, os valores, o conhecimento sobre as matérias que ensinam e como as ensinam, as experiências passadas, assim como a própria vulnerabilidade profissional". (ANDRÉ, 2015, p.176)

Nas situações em que a captação da realidade, de seus elementos constitutivos, se dá em forma mais 'admiradora' do que 'aderida', situações em que, o nível de segurança e do êxito da ação já está captado pela experiência, as formas mágicas são desprezadas. Nem sempre a formação sendo ela objetiva provoca compreensão verdadeira dos fatos, pois mesmo associada a uma dada ação a captação dos nexos nem sempre se dá de forma verdadeira. Seja no domínio da pura 'doxa', seja no domínio do pensar mágico, estamos em diante de formas ingênuas de captação da realidade objetivas e desarmadas em face de formas de pensamento de cada um. A formação corre o risco de permanecer com o comportamento mágico em detrimento de uma forma crítica de pensar se existir equívoco gnosiológico.

Essa proximidade com o mundo natural, mágico pode dificultar a operação de 'ad-mirá-lo', na medida em que a proximidade não lhes permite ver o 'ad-mirado' em perspectiva. A captação dos nexos que prendem um fato a outro, entre o desejo daquilo que projetou para si e a opção pela formação não

UNESC, Criciúma, v. 5, n¹, janeiro/Junho 2016. Criar Educação - PPGE UNESC 


\section{Criar Éducaçãa}

podendo dar-se de forma verdadeira, embora objetiva, provoca uma compreensão também não verdadeira dos fato que por sua vez, está associada a ação mágica.

É por meio de significados que o mundo, a educação, a identidade e a diferença nos torna conhecidos, inteligíveis e diferentes uns dos outros. Os significados são produzidos pela linguagem no campo social, não são neutros ou desinteressados; pelo contrário, eles são disputados e produzidos nas relações de poder. "Os significados carregam a marca do poder que os produziu". (SILVA, 1996, p. 170).

Nas relações com o mundo, através de sua ação sobre ele, o homem se encontra marcado pelos resultados de sua própria ação. Atuando, transforma; transformando cria uma realidade que por sua vez, 'envolvendo-o' condiciona sua forma de atuar. Não há, por isso mesmo, possibilidade de dicotomizar o homem do mundo, pois não existe um sem o outro.

Quanto mais alguém, por meio da ação e da reflexão, se aproxima da 'razão', do 'logos' da realidade objetiva e desafiadora, tanto mais, introduzindose nela alcançará o seu desvelamento. Quando nos mantemos distantes do conhecimento estamos nos preparando para uma existência vazia. Se não pretendemos nos atualizar, não estudarmos, não nos abrimos para conceber coisas novas, se não estamos prontos para aprender a aprender - aprender a fazer e aprender a ser - não evoluímos para o crescimento pessoal. Portanto, é preciso possuir o desejo de crescimento, buscar sempre 0 ato do conhecimento, como investimento pessoal e profissional. É necessário termos como princípio de vida o estudo, a leitura, o registro, para poder nos elucidar no desejo de nos conhecermos em múltiplas direções.

A reflexão está relacionada com a capacidade intelectual dos professores ao enfrentar situações incertas e desconhecidas como elaboram e modificam rotinas, experimentam:

A relação com nós mesmos é uma tarefa de construções e desconstruções, um projeto de vida. Basta ter presente o quanto

UNESC, Criciúma, v. 5, n¹, janeiro/Junho 2016. Criar Educação - PPGE UNESC 


\title{
Oriar Goducaçãa
}

\begin{abstract}
temos que desconstruir (para reconstruir!) no que diz respeito a instruções travestidas de educação que recebemos de responsáveis por instituições como família, escola e igreja e que têm no aparato jurídico o baluarte de sua manutenção, caso haja alguma tentativa na direção daquilo que o grupo dominante considera um desvio. (BIANCHETTI, 2002, p. 4)
\end{abstract}

Para o autor é no ambiente escolar que se dá uma das maiores mediações: a passagem da heteronomia para autonomia, na primeira vive-se a situação em que estamos susceptíveis às opiniões dos outros por viver o coletivo e dependentes física ou emocionalmente dos outros e, na segunda, a autonomia é a meta desejável e necessária para o processo de criação e socialização.

\section{A aprendizagem não formal e as estratégias para a autoformação.}

Em palestra recente, Carlos Marcelo Garcia (2013) da Universidad de Sevilla afirma que a sociedade de hoje disponibiliza a todos aqueles que desejam o acesso a recursos em qualquer momento de sua vida, assim como proporciona a todos os que querem compartilhar seus saberes, o poder de encontrar aqueles que querem aprender com eles.

Realmente a sociedade, especialmente nesse século XXI disponibiliza estratégias facilitadoras e ambientes pessoais de aprendizagem dentre os quais podemos citar; os Mundos Virtuais, Redes Sociais, Jogos, Celulares, Portfólio, as TICs, Web etc.

Por outro lado, o aprendente ativo desenvolve novas competências por iniciativa própria motivado por várias razões, dentre elas podemos citar: o trabalho que desenvolve em equipe, a busca para solução de erros cometidos, o desejo ou necessidade de desenvolver novas competências, por criatividade pessoal, pelo desejo de colaborar em comunidade. Em qualquer momento e lugar pode-se combinar o mundo físico e o virtual desenvolvendo novas formas de aprender em qualquer momento e lugar, pois a aprendizagem ocorre ao longo da vida.

UNESC, Criciúma, v. 5, n¹, janeiro/Junho 2016. Criar Educação - PPGE UNESC 


\section{Criar Éducaçãa}

Garcia (2013) cita várias aprendizagens que corroboram para a autoformação: a aprendizagem tácita, aprendizagem na prática, aprendizagem autodirigida, autodidata, aprendizagem ao longo da vida, aprendizagem incidental, aprendizagem adulta, aprendizagem autônoma, auto aprendizagem, aprendizagem aberta, aprendizagem pela experiência, aprendizagem informal, aprendizagem autorregulada. São diferentes modos de aprendizagens existencial e pedagógica disponíveis, que pode ser experenciada por aqueles desenvolvem o processo de emancipação crítica e que optam por aperfeiçoar a própria formação.

Portanto, podemos considerar que a autoformação é o investimento que o sujeito faz a si mesmo a partir do momento em que toma consciência das suas necessidades e dificuldades consideradas como limites situacionais, impedindo ou impulsionando-o para mudança transformando-as em possibilidades de mudanças.

\section{Considerações Finais}

A relação consigo mesmo é uma tarefa de construção e desconstrução, um projeto de vida. Basta ter presente o quanto temos que desconstruir para reconstruir! O caminho formativo decorre das instruções travestidas de educação que recebemos de responsáveis por instituições como; família, escola e igreja que têm no aparato jurídico o baluarte de sua manutenção além do conjunto das culturas e as regras existentes vão desenhando o modo peculiar, pessoal e individual da história de cada um.

Nas relações com o mundo, através de sua ação sobre ele, o homem se encontra marcado pelos resultados de sua própria ação. Atuando, transforma; transformando cria uma realidade que, por sua vez, 'envolvendo-o' condiciona sua forma de atuar. Não há, por isso mesmo, possibilidade de dicotomizar o homem do mundo, pois não existe um sem o outro. O autoconhecimento, a autoformação e a formação vão delineando nossa identidade e o que construímos a partir do nome que nos é dado ao nascer.

UNESC, Criciúma, v. 5, n¹, janeiro/Junho 2016. Criar Educação - PPGE UNESC 


\section{Criar Éducaçãa}

Descortinar os modos de formação, os contextos, realidades possíveis narradas/contadas pelas histórias de vida nos faz compreender que a formação inicial não é a única responsável por formar o professor. Existem outros fatores que contribuem para a formação, pois ninguém está sozinho e ao longo da vida recebe influencia da família, dos professores, da sociedade, das políticas, ou seja, de todos os âmbitos sociais. E, para os que desejam, o percurso formativo pode ser enriquecido pela autoformação.

\section{REFERÊNCIAS}

ANDRÉ, Marli. Formação de professores:a constituição de um campo de estudos.Educação,Porto Alegre, v. 33, n. 3, p. 174-181, set./dez. 2010. Disponível em:

<http://revistaseletronicas.pucrs.br/ojs/index.php/faced/article/view/8075/5719>. Acesso em: 02 set. 2015.

BIANCHETTI, Lucídio. UM OLHAR SOBRE A DIFERENÇA: As múltiplas maneiras de olhar e ser olhado e suas decorrências. Revista Brasileira de Educação Especial, Marília, v. 8, n. 1, p. 1-8, 2002. Disponível em: <http://www.propp.ufms.br/ppgedu/geppe/artigo2.pdf>. Acesso em: 02 set. 2015.

BORDIGNON, G.; GRACINDO, R. V. Gestão da educação: o município e a escola. In: FERREIRA, Naura S. C.; AGUIAR, Márcia A. da S. (Orgs.) Gestão da Educação: impasses, perspectivas e compromissos. São Paulo, Cortez Editora, 2009.

BOSI, E. Memória e Sociedade: lembranças de velhos. São Paulo: Cia das Letras, 1983.

DEWEY, J. Democracy and Education. New York: Macmillan, 1916.

FAZENDA, Ivani Catarina. Interdisciplinaridade: um projeto em parceria. São Paulo, Edições Loyola, 1991.

FAZENDA, Ivani Catarina. Interdisciplinaridade na formação de professores: da teoria à prática. Canoas, RS:ULBRA, 2006.

FREIRE, P. A Pedagogia do Oprimido. Rio de Janeiro: Paz e Terra, 1974.

GARCIA, Carlos Marcelo. Desenvolvimento Profissional: passado e futuro. Sísifo- Revista das Ciências da Educação, n. 08, p. 7-22, jan./abr. 2009. Disponível em: <https://www.researchgate.net/profile/Carlos_Marcelo/>. Acesso em 12 set. 2015.

HALL, Stuart. A identidade cultural na pós-modernidade. $7^{\mathrm{a}}$ ed. Rio de Janeiro: DP\&A, 1997.

UNESC, Criciúma, v. 5, n¹, janeiro/Junho 2016. Criar Educação - PPGE UNESC 


\section{Criar Éducaçãa}

JOSSO, Marie C. História de vida como projetos e as histórias de vida a serviço de projetos. Revista Educação e Pesquisa, São Paulo/SP, v. 2, n. 2, p. 11-23, jul/dez. 1999.

LARROSA, J. Pedagogia profana: danças piruetas e mascaradas. Belo Horizonte: Autêntica, 1999.

SEVERINO, A. J. Educação, sujeito e história. São Paulo: Olho d'Água, 2002.

SILVA, T. T. Alienígenas na sala de aula: uma introdução aos estudos culturais em educação. Petrópolis: Vozes, 1996.

VEIGA-NETO, A. Crítica pós-estruturalista e educação. Porto Alegre: Sulina, 1995.

UNESC, Criciúma, v. 5, n¹, janeiro/Junho 2016. Criar Educação - PPGE UNESC 